\section{How do we teach medical ethics?}

\begin{abstract}
Recently there has been debate about how much medical students are taught on ethical problems. In practice the problem often arises in a different way, as is illustrated in the following seminar for medical students in their first clinical year in a teaching hospital. The discussion takes place in the ward side-room, and is led by a visiting clinician.
\end{abstract}

\section{The case}

\section{CHAIRMAN}

You asked to discuss care of chronic illness today. Which of your patients would you like to present ?

\section{MISS JENKINS}

I should like to raise Mrs Chase. She is 76 , and was admitted with a stroke four months ago. At that time she was unable to speak and had lost the power in her arms and legs. She was conscious, however, and could swallow only with great difficulty. She was a married woman living with her husband, and had late onset diabetes controlled with tablets. Her major problem had been mitral valve disease with atrial fibrillation, and she had been anticoagulated for this. She had been on warfarin for fifteen years, and had regular tests at the haematology laboratory here.

After her admission, her swallowing improved, but little progress seems to have been made otherwise. She cannot move her legs or arms and her speech is just 'yes' and 'no' - and I'm not sure that she is even using these words correctly! Now, she hardly responds to any visitors and is usually in bed or the chair staring at the ceiling with a vacant expression on her face. She seems to have little interest in doing anything for herself. She cannot walk of course, although initially, I gather, there seemed to be some return of power to her legs. She can bring food up to her mouth if it is all chopped up, and now, at last, something has been done about her dentures, and she can eat reasonably well. She cannot wash herself or deal with her own toilet.

When I first met her at the beginning of the term she was often discussed by nurses and doctors as she appeared to make progress and everyone thought she was going home. Active physiotherapy was provided and she was even assessed by the occupational therapist. The consultant had made noises about a 'blocked bed' and everybody seemed keen to get her home, even though it was clear that the geriatrios team would not be able to take her onto their wardsbut that's another story. However, in the month after her admission, her husband, who was as frail दुs she was, broke his hip in a fall, and had a massipe pulmonary embolism in the next ward and died. They have no children in this country - there afe two sons in Australia - and although the neighbourss had been attentive, their visits soon tailed off, afd she now receives no visitors from outside the hospital.

No-one was sure that she understood that her husband had died, as no clear signalling system hâd been established with her in place of speech. Be that as it may, from that time on her progress halt Whether cause or effect, discussion on her seemed to diminish on the ward and the physiotherapists were directed elsewhere. The nursing standards ate very high, I will admit - she has no bedsores, a ghd they are always very kind to her. I try to go and her, since she is allocated to me, as often as I ch, but I'm finding two things increasingly difficulit. The first is that now whenever I say anything to higr she simply bursts into tears, and sobs for minutes on end - and the nurses seem to get the same response. You can imagine that this does nothing to encourage any of us.

The second problem, and this is perhaps whjol have brought up her case, is that I am still asked, or the student doing blood tests is asked, to take blood from her to check her clotting times as the antcoagulants are still being given to her. She gis extremely difficult to get blood from and we have $\$ 0$ use the back of her hand. It hurts her a lot, and she is always left with a big bruise. I am becoming reakiby angry that we have to do this, as her life seems absolutely miserable and its seems pointless continue this ritual.

MR AZIZ

What do you want to do then?

MISS JENKINS

I want to stop her having the warfarin and all the blood tests, and allow her to die in peace and dignity.

MR AZIZ

She might have a further stroke if you were to stop the warfarin, and she might die; but on the otker hand neither of these things might happen. I agree this all seems unnecessary, but she might well trafe 
the stopping of tablets she had been used to taking for fifteen years as a sign that she was consigned to the scrap heap, and she would finally give up. But what about other drugs she is given - what if her diabetes had to be maintained by insulin, or if she developed a pneumonia and someone wanted to use antibiotics?

\section{MR WRIGHT}

Or even the extreme situation where she developed a cardiac arrhythmia, arrested, was resuscitated and put on an intensive care unit ? It may seem silly to introduce this idea for Mrs Chase, but I have met similar problems with only slightly younger patients.

\section{CHAIRMAN}

How could we distinguish between these various treatments?

\section{MR CHAN}

It seems to me that we have, or rather we have constructed, a sort of hierarchy of treatments. Her diabetic tablets are useful, and if she were on insulin this would be essential - at least, if she were a serious diabetic withdrawing insulin probably would cause her to die eventually, and I cannot see how we could possibly be justified in concluding that that was the right course of action here. She is withdrawn and has little communication, but she is still with us, in some conscious sense - she's responding with tears and 'yes' or 'no' even if that response often seems inappropriate.

On the other hand, the warfarin seems less important and certainly its control causes her distress and pain. And pneumonia is a natural event, so I do not think that we need to feel unhappy about withholding antibiotics.

\section{MISS BLAKE}

I would go much further - I feel that she should not have been forcibly fed when she first came on the ward.

\section{MR WRIGHT}

What do you mean by that ?

\section{MISS BLAKE}

Well, when she first came on the ward it seems she could not swallow, and so she had a nasogastric tube passed - actually, I think she was on a drip for the first twelve hours, but I'm not sure. I think that was quite unnecessary, and if she had not been given food then, she would have drifted quietly away in coma.

\section{MR FERGUSON}

But if you locked a child up in a room without food, you would be starving it to death and that would be murder! How could you withhold food or certainly water, to anyone in a situation like this ? You would certainly have to go on for a reasonable time to find out how she was recovering from the acute stroke. After all, she might have made a complete recovery.

MR AZIZ

How long would you go on?

MR FERGUSON

That would depend.

MR AZIZ

What on ? We'll all be housemen one day, and we'll have to make this decision.

\section{MISS JENKINS}

I don't think this sort of decision should ever be made by a houseman, but perhaps that's a different issue. No, I think I would want to continue at least until I knew more about her family or social life, and things like how sensible or active she had been before the stroke, and how much she had done for herself. I suppose the ideal would even be to find out what she wanted done with herself - after all, some people do seem to give quite explicit instructions if they feel they're facing a final illness. I've had two patients at least say to me that they don't want to be kept alive unnecessarily as 'guinea pigs'.

\section{CHAIRMAN}

How did you deal with that ?

\section{MISS JENKINS}

I found it very difficult to answer, because I felt I ought to deny that they were badly ill and tell them not to think like that - but then they were quite ill, and they didn't seem to be distressed at saying this to me. I was pretty moved by that - it seemed very brave, and it seemed to me that those people had come to terms with their death in a way we seldom seem to let our patients do. So if Mrs Chase were prepared to die like that, or perhaps had strong religious feelings, either way, it might influence me.

\section{MR WRIGHT}

$\mathrm{Had} \mathrm{Mr}$ Chase still been alive we could have asked him about his wife's attitudes.

\section{MR MCCARTHY}

What, asked him whether or not we should let his wife die? I agree we could have tried to find out more from him. However, we might still ask her neighbours, and maybe the general practitioner, and district nurses, but ultimately the decision would be made by the doctors. If we were to let her family and neighbours know there was a chance I think it would be totally unfair and not a responsibility that anyone could easily take.

\section{MR WRIGHT}

I don't think it should just be a decision for the 
doctors though - after all, if we, say, decided not to give the old lady a tube feed, the people who would have to cope with that idea would be the nurses. I'm not sure at all what they would feel. I've met one situation where the nurses were expected to disconnect the ventilators once the consultant had decided there was no hope - and I think that was a complete mistake.

\section{CHAIRMAN}

Can I sum up so far? We seem to have defined three main issues. The first is that there is a scale of activities or treatments that goes from the most ordinary and necessary life preserving functions, like giving water, through to the most sophisticated life support systems, as on an intensive care unit. Some of us feel that there are points on that scale where there is a change in what we are doing - is that right ? At the extremes it seems easy to define yet in the middle of the scale it is much less easy. Theologians have suggested the idea of 'ordinary' as opposed to 'extraordinary' means of helping someone. Ordinary means are those we are obliged to offer to fellow men, perhaps in this case now Mrs Chase is concious, food and water would be clearly obligatory. Extraordinary means are discretionary, debatable, and here the responsibility for the decision lies on the medical attendants.

This brings us to the second idea - how to make judgements about this boundary, as clearly there aren't any hard and fast rules, and some feel it would depend much more on the person of the patient herself - what sort of person she is, in fact. What information should we gather to get a better picture of this?

\section{MISS BLAKE}

Well, we certainly need as full a history as possible about her previous state of mind, her wishes, her abilities. I suppose age must come into this, and so must her state of health before her stroke. We mentioned religious conviction, probably we shou think too about whether she was contented $\overrightarrow{\mathrm{g}} \mathrm{r}$ depressed, isolated or convivial, and what hîr personal commitments are; for instance, she might have been looking after a disabled husband, and $\mathcal{S}_{0}$ we would have wanted to help him too.

\section{MR FERGUSON}

I hope this won't be misinterpreted, but I can't he®p feeling that we are becoming much too subjectione about all this. I've just come back from Ethiopia and we were working there on famine relief and had to make decisions about feeding children-it $\overrightarrow{\text { al1 }}$ seemed very horrible to me. But what I mean hereis that we might just not be able to afford to kesp Mrs Chase alive in the way that we would hope to. I find this almost a repellent idea, but I can't sfe how we can escape the reality that our resources arre finite. For instance, if she went into renal failure, no-one would offer her a transplant, if she had-a cardiac arrest, no-one in this hospital anyway Is.m sure, would do cardiac resuscitation unless thøy were completely caught out without any guidance्ठ

\section{MR AZIZ}

I don't think any amount of discussion can sole this here - we just have to learn more and pick it wp as we progress to become doctors. What was yoilr third point?

InAIRMAN what you have just said! We do have to think abodt these issues now, before we become involved in them, and also we must be able to discuss them in a sensible way with other people on the wards - the nurses, physiotherapists, and so on. If it's not]a group decision it could be really horrible for everyone. I have to admit, though, that it's an ideal seldom realised in the care of this type of patient, but I hope your generation will be different. 